\title{
MOOC Teaching-A New Teaching Model in the Age of Big Data
}

\author{
Yang Zhao \\ School of Management, Shenzhen university \\ Shenzhen, China
}

\begin{abstract}
Nowadays, with the rapid update of knowledge, the traditional teaching methods are difficult to meet the teaching requirements of the new era. How to change teaching methods has become an important issue to colleges and universities. As an educator, the author explores the application of MOOC in Colleges and universities through a comprehensive understanding. Through the study of its characteristics, teaching modes and effects, this paper points out the influence and change of MOOC on traditional teaching methods. MOOC, as a new mode of education formed by the combination of education and technology, provides learners with a new channel of knowledge acquisition and learning methods, and becomes a new way for people to learn in the era of big data. It is exerting tremendous influence and change on higher education.
\end{abstract}

Keywords-MOOC; Big data; Teaching model; Educational reform

\section{INTRODUCTION}

With the development of information technology, the digital world is expanding at an unprecedented rate. YouTube receives as many as 800 million visitors a month, with an average video upload of more than an hour per second [1]. Every day, people comment or comment on Facebook about 3 billion times. The speed of data expansion has exceeded people's imagination, and people are increasingly dependent on data for work and life. Various signs indicate that the era of big data has arrived.

The most prominent feature of the big data era is that the use of data becomes simpler. Individuals can acquire and produce new data anytime, anywhere, and it is easier to extract information into knowledge, thus gaining insight and value. So big data is affecting people's working methods and thinking habits more and more profoundly, and leading them to make significant changes. The new characteristics of the era of big data make it possible for higher education teaching reform. Without data retention and deep mining education information can only become a formality[2]. The rapid development of information technology and the generation of big data can enable education to mine and use data information from multiple perspectives and in-depth. The information age is changing our world step by step, and even the traditional teaching mode that has lasted so far is being quietly broken.

\section{The CONNOTATION OF MOOC}

The widely accepted definition of MOOC is that large-scale open online courses are online courses aimed at large-scale students' interactive participation and open resource acquisition based on the network. In MOOC teaching mode, not only video resources, but also text materials and online questions answering can be provided. In addition, it can also provide learners with a variety of user interaction communities and establish interactive participation mechanisms [3]. The term MOOC originated in 2008. It was proposed by Dave Cormier of Prince Edward Island University in Canada and Bryan Alexander of the National Institute of Advanced Studies in the Application of Humanities and Educational Technology on the basis of innovative teaching practices in online courses[4]. Such teaching form has been widely participated in and recognized. Under the impetus of the United States, universities all over the world have joined this teaching camp. Spain, Australia, South Korea, Germany, India and other countries have also developed their own MOOC teaching platform. Due to the promotion of universities in various countries, MOOC has been paid more attention by more countries and colleges. In China, this teaching method has also been adopted by many colleges and universities.

Compared with the traditional teaching mode, MOOC has its own unique characteristics, which are as follows:

(1)Large scale. "Large-scale" means a large number of students. The students who participate in the study are not only the same school, but also the same hobby enthusiasts all over the country or the world. This leads to a huge number of audiences participating in learning at the same time. On the one hand, it solves the problem that students are unable to attend classes, on the other hand, it also solves the problem of the shortage of teaching resources. For the first point, because the network accommodation space is infinite, there is no boundary, so students can choose their favorite courses without restriction. For the second point, the shortage of teaching resources is a common problem faced by most schools. The problems of insufficient classroom resources and insufficient teachers' resources are particularly prominent today when the number of students become more and more. "Large-scale" also means huge amounts of data. MOOC's teaching openness means that all teaching courses and teaching resources are open to all, not limited to certain groups. This will inevitably produce a large amount of data information, and the workload of processing these information is also very large. Now, benefiting from the rapid development of big data technology and information technology, these problems can be easily solved, which makes the use and promotion of MOOC possible.

(2)Interact in a timely manner. Previously, some courses have realized network-based teaching, but the traditional network-based teaching method is fundamentally different from MOOC's network-based teaching. Previous distance 
courses were taught unilaterally, and instant interaction could not be achieved, while MOOC realized instant interaction[5]. The reason why MOOC can achieve such a revolutionary and creative breakthrough lies in the development of big data technology and the continuous innovation of information technology.

\section{Classification OF MOOC}

Because of MOOC develops very rapidly, there are many different classifications. Different courses have different emphasis in teaching design. Some focus on design concepts, others on the scope of dissemination. According to the classification method of learning theory, MOOC can be divided into cMOOC based on relevance learning theory and xMOOC a new development course based on behaviorism theory.

(1) cMOOC based on relevance learning theory. The characteristics of such courses are as follows: based on thematic, focuse on knowledge construction and creation. Course organizers set learning themes and guide them from three stages: pre-class, in-class and after-class. In this way of learning, emphasis is placed on creativity, autonomy and social network learning. Students should show strong autonomy in cMOOC, be able to spontaneously establish learning channels with others and have the ability to communicate and collaborate. In the process of learning, each student can construct knowledge individually and build a suitable learning network. In this curriculum model, the curriculum structure is constructed from the learning content. The curriculum content is often unstructured. Students expand the learning content by sharing and exchanging resources. In this way of learning, students take sharing and creating knowledge as their learning objectives. Distributed social media (microblogging, discussion groups) are used to support extracurricular discussions.

(2)New development course xMOOC based on behaviorism theory. It is mainly represented by three major MOOC institutions in the world: Coursera, Udacity and edX.

The characteristic of this kind of curriculum is that it is content-based. Generally, teaching is carried out by adopting a large number of typical cognitive-behaviorism teaching methods. In this way of learning, emphasis is laid on knowledge dissemination and replication. Emphasis is placed on learning methods such as video, homework and testing. Teachers regularly release videos specially recorded for xMOOC courses. These videos are usually relatively short, in which learning problems and tests are arranged. Students mainly learn by watching teaching videos, and cooperate with online determine and review, peer assistance and programming exercises to achieve learning objectives and master learning content. At the same time, online websites also set up discussion groups and organize offline meetings. Students can communicate online and cooperate with off-line learning and discussion. In this way of learning, students aim at mastering the learning content. The course-based centralized forum and offline meeting are adopted to complete the extracurricular discussion.
Nowadays, more and more people in China are participating in foreign open course learning. Most xMOOC websites provide video subtitles, especially many xMOOC websites provide multi-language subtitles, which further stimulates the enthusiasm of domestic learners to participate in learning and effectively promotes the development of xMOOC websites in China.

\section{Educational Changes Brought By MOOC}

\section{A. Openness of Teaching Model}

Compared with traditional teaching methods, MOOC teaching based on network has a strong open character. Traditional teaching mode has strong regional characteristics, students can only stick to tangible reinforced concrete. Although there are many excellent experts and scholars in the teaching guidance, but due to geographical reasons, only a very small number of students are lucky to participate in learning. The openness of the network also makes the learning mode open. Teaching is no longer aimed at a specific minority, but has become a common resource of the society. This change in teaching mode makes the dream of "learning without borders" come true.

As an open type of curriculum, MOOC, supported by information technology, provides new open curriculum resources and learning methods with the participation and promotion of social institutions and educational institutions, and constructs a learning ecosystem composed of social environment, technological environment and teaching environment [6]. Learning is not only an instinctive need of human beings, but also a need for individual growth. However, in the traditional education mode, this kind of individual needs are often ignored and can not be met. The teaching mode based on MOOC is changing this situation. It is no longer impossible to study in world famous schools. Open educational resources make it possible for anyone to acquire knowledge from the data platform as long as they have the willingness to learn.

Although the previous online education can also achieve some of its functions. But the characteristics of real-time interaction and big data technology give MOOC a completely different picture and effect from online education. Therefore, the founder of EDX believes that "this is a major technological progress rarely seen in the field of learning" [5]. It is also because of the continuous improvement of big data and information technology that MOOC's "large-scale" teaching can be successfully realized. Students all over the world can analyze and discuss a problem at the same time. This forms a new learning community larger than the traditional classroom. Compared with the traditional teaching mode, MOOC has achieved great changes in teaching methods. The dynamic balance between learning self-organization and other-organizations has been achieved.

\section{B. Autonomy of Learning Style}

MOOC teaching provides guarantee for students' individualized and autonomous learning. In the environment of large data, knowledge is networked. Learner learning is characterized by interactive learning based on social network media, unstructured curriculum content, emphasis on the establishment of learning channels, high autonomy of learners 
and spontaneity of learning [6]. Students can draw up their own learning plan according to their actual situation, determine their own learning goals, choose teachers and curriculum content according to their actual situation, so that learning can really be different from person to person [7]. Each learner can select and match learning elements according to his own actual situation, and complete the individualized construction of knowledge. For students' individualized learning guidance, such as what are the common mistakes and what are the effective learning paths, it depends on big data technology to achieve. The rapid development of big data technology and data mining technology has provided great help for the improvement of students' learning effect and the support of personalized learning, and further realized the improvement and optimization of traditional education mode

Traditional teaching methods usually aim at one-way transmission and replication of knowledge, and do not fully respect students 'autonomy and enthusiasm, which seriously hinders the formation of students' active learning ability. MOOC teaching emphasizes "student-centered", and its teaching mode has bold innovation. The network curriculum based on big data and information technology is changing from the solidified curriculum resources to the dynamic generative network school, and students are changing from negative knowledge consumers to knowledge producers, forming a new super-cycle learning culture [8]. All these help to give full play to the students' main role and enhance their subjective initiative.

\section{Teaching Mode of Flipping Classroom}

In MOOC teaching, the teaching mode of flipping classroom is adopted, which can promote the improvement of students' reflective ability. In the traditional teaching mode, the cramming teaching method is mainly used. Teachers teach students what to learn and the learning method is often very passive, which seriously shackles the formation and improvement of students' ability to analyze and solve problems independently. MOOC teaching actively advocates students' active learning through the establishment of learning community and mutual learning platform, and provides a platform for students' active thinking and knowledge upgrading through continuous reflection, exchange, discussion and mutual evaluation of the courses. The learners' mastery of the knowledge is constantly strengthened, and they can actively apply it to practical application. At the same time, in the process of learning, students find problems through independent thinking, and can use various methods and means, through their own efforts and the mutual assistance of classmates, research problems and analyze and solve problems, in the process of improving their ability to analyze and solve problems. To enable students to grasp the methods of solving problems in active thinking, and enhance their cognitive ability of knowledge and problems.

In the flipped classroom model, teachers use autonomous learning, demonstration, conversation, discussion and other teaching methods, using Curriculum Center website, curriculum discussion space, virtual teachers and other technical means, which is conducive to the interaction between teachers and students, and improve learning efficiency [9]. At the same time, this model strengthens students' learning motivation and meets their emotional needs. Students said that the classroom "a lot more interaction with teachers, vivid classroom can make me more motivated to learn"; "deeply realize the importance of pre-class preparation, gradually have the courage to speak in class" [10]. At the same time, by means of multi-channel communication and feedback and more interactive communication, the mode of flipping classroom has greatly improved students' ability in language and skills. In this process, through " Learn from finding problems " and " Learn from problem solving ", students are encouraged to actively participate in the whole teaching process, and students' enthusiasm for learning is fully mobilized to form a good atmosphere for active learning.

\section{Improvement of Learning Effect}

The emergence of MOOC has brought about changes in teaching methods. With the help of big data and information network, a new teaching mode of "open environment autonomous learning - comprehensive ability enhancement" has been formed. In this process, students' ability of autonomous learning is brought into full play, and the teaching effect can be improved.

MOOC teaching is not only limited to traditional face-to-face teaching, but also pays more attention to online course learning using network technology. It realizes the integration of online learning and offline learning. This way of learning can promote students to participate more actively in the whole process of teaching and learning. In 2010, the U.S. Department of Education conducted metadata analysis of 50 published studies on online learning and face-to-face learning. According to the research results, a research report entitled Online Learning Assessment Based on Practical Evidence: A Review of Metadata Analysis and Online Learning Research was published. The results show that, on average, students perform better in online learning than in face-to-face learning, and the hybrid education using both methods is more effective than online or face-to-face education alone [11]. In addition, San Jose State University has released data on a campus exam. Data analysis shows that under the learning mode of combining offline teaching with online learning, the passing rate of students has increased from $55 \%$ to $91 \%$.

Compared with the traditional teaching mode, MOOC teaching also constructs a learning community, which provides a platform for learners to help each other communicate. Learners can not only learn knowledge on the Internet, but also set up an offline learning group. In this way, learners can ask and answer questions with each other. Such as Edx, an educational website launched by Harvard and MIT in 2012. Its essence is a non-profit network platform which provides students with online interactive communication. The platform has attracted more than 600,000 students from 12 universities around the world. In this platform, collaborative learning functions are specially set up and online learning groups are set up too. Through collaborative learning and group learning, students can help each other, exchange learning experience, answer questions, and communicate with each other. In this way, students can better grasp the knowledge they have learned, solve various problems encountered in learning as soon as possible, strengthen the learning effect and speed up the learning progress. Students feel that such a way of learning 
is of great help to their own learning. For example, experts tracked 87 engineering students from San Jose State University who took part in online courses as well as in offline learning groups to discuss and communicate through group learning. The survey results show that students can better understand the knowledge points in teaching, deepen the understanding of the curriculum content, and promote the teaching effect to a large extent.

In MOOC teaching, the evaluation methods of self-evaluation and mutual evaluation are also established by means of intelligent evaluation. Courser's innovative peer-to-peer evaluation mechanism of online curriculum has changed learners from passive evaluators to active evaluators, which not only reduces the burden of teachers, but also improves the enthusiasm of students to participate in learning [8]. Philip M. Sadler (2006) experimental research shows that appropriate incentives and evaluation can promote learners' learning, while protecting learners' privacy, learners' mutual evaluation can also benefit [11]. By adopting such a checking and evaluating mechanism, learners can improve their learning situation in time. This mechanism has become an effective way to mobilize learners' learning enthusiasm.

\section{CONCLUSION}

The drawbacks of traditional teaching have become more and more serious. In order to solve these problems and stimulate learners' initiative and creativity, MOOC has emerged in this context. As a new mode of education formed by the combination of education and technology, it adopts the way of inspiration, guidance and dynamic collaboration to communicate and learn, which effectively stimulates students' autonomy and greatly improves the teaching effect. Therefore, in the Internet era, whether it is learning model or education model, only continuous innovation can adapt to the changing era.

\section{REFERENCES}

[1] Jin Ling, Big Data and Informatization Teaching Reform. Theory and Controversy, 2013.6(10):p.8-13. (In Chinese)

[2] Tu Zipei. Big Data: The Coming Data Revolution. Guilin: Guangxi Normal University Press, June-7, 2012. (In Chinese)

[3] McAuley. A, Stewart .B, Siemens .G\& Cormier. D (2010).The MOOC Model for Digital Practice [DB/OL] [2013 -04 -16].http://www.e-learnspace.org/Articles/MOOC_Final.pdf.

[4] Massive Open Online Course [EB/OL].[2015 -05 -1] http://en.wikipedia.org/wiki/ Massive_open_online_course.

[5] Su wan, Luo Yan. Technological Myth or Educational Revolution: The Impact of MOOCs on Higher Education. Education Research of Tsinghua University, 2013,34(4): p.6-12. (In Chinese)

[6] Wang Ping. New Development and Application of Large-scale Online Open Courses: from cMOOC to xMOOC. Modern Distance Education Research, 2013(3): p.13-19. (In Chinese)

[7] Zhao Yang. An Analysis of Network-based Distance Teaching Model [C]. Li li. Collection of Research Papers of School of Management, Shenzhen University. Guangzhou: Jinan University, 2013: p.194-198. (In Chinese)

[8] Wang Ying, Zhang Jinlei, Zhang Baohui. Analysis and Enlightenment of Typical Project Characteristics of Large-scale Open Online Course (MOOC), Journal of Distance Education, 2013, 4 (9): p.67-75. (In Chinese)

[9] Zheng Hongmei, Research on the Construction of Students Self-regulated Learning Ability Based on the Teaching Resources of "Mu Course". Student Management, 2015 (6): p.226-233. (In Chinese)

[10] Hu Jiehui, Wu Zhongjie. Research on MOOC-based Flip Classroom Teaching Model for College English. Foreign Language Audiovisual Teaching, 2014 (160): p. 40-44. (In Chinese)

[11] Zhu Zhiting, Yan Hanbing, Wei Fei. Looking at the Positive Energy of Open Education in MOOCs. Research on Open Education, 2013, 19 (6): p.18-26. (In Chinese) 